\begin{tabular}{|l|l|}
\hline Title: & Post-Punching Behavior of Flat Slabs \\
\hline Authors: & Fernández Ruiz M., Mirzaei Y., Muttoni A. \\
\hline Published in: & ACI Structural Journal \\
\hline $\begin{array}{l}\text { Volume: } \\
\text { Pages: }\end{array}$ & $\begin{array}{l}\text { V. } 110 \\
\text { pp. } 801-812\end{array}$ \\
\hline Country: & USA \\
\hline Year of publication: & 2013 \\
\hline Type of publication: & Peer reviewed journal article \\
\hline
\end{tabular}




\title{
Post-Punching Behavior of Flat Slabs
}

\author{
by Miguel Fernández Ruiz, Yaser Mirzaei, and Aurelio Muttoni
}

\begin{abstract}
Reinforced concrete flat slabs are a common structural system for cast-in-place concrete slabs. Failures in punching shear near the column regions are typically governing at ultimate. In case no punching shear or integrity reinforcement is placed, failures in punching develop normally in a brittle manner with almost no warning signs. Furthermore, the residual strength after punching is, in general, significantly lower than the punching load. Thus, punching of a single column of a flat slab overloads adjacent columns and can potentially lead to their failure on punching, thus triggering the progressive collapse of the structure. Over the past decades, several collapses have been reported due to punching shear failures, resulting in human casualties and extensive damage. Other than placing conventional punching shear reinforcement, the deformation capacity and residual strength after punching can also be enhanced by placing integrity reinforcement to avoid progressive collapses of flat slabs. This paper presents the main results of an extensive experimental campaign performed at the Ecole Polytechnique Fédérale de Lausanne (EPFL) on the role of integrity reinforcement by means of 20 slabs with dimensions of $1500 \times 1500 \times 125 \mathrm{~mm}(\approx 5 \mathrm{ft} \times 5 \mathrm{ft} \times 5 \mathrm{in}$.) and various integrity reinforcement layouts. The performance and robustness of the various solutions is investigated to obtain physical explanations and a consistent design model for the load-carrying mechanisms and strength after punching failures.
\end{abstract}

Keywords: deformation capacity; flat slabs; integrity reinforcement; punching shear; shear reinforcement.

\section{INTRODUCTION}

Over the past decades, several collapses due to punching shear failure have been reported in Europe and America, ${ }_{1}^{1}$ resulting in human casualties and extensive damage. In Switzerland, in the late 1970s, the punching failure of a slab during the construction phase led to the progressive collapse of a large part of a shopping center (Fig. 1(a)). In the winter of 1981, another collapse occurred at an underground parking garage in Bluche, Switzerland, which caused the death of two children (Fig. 1(b)). On November 27, 2004, a catastrophic collapse occurred in an underground parking garage in Gretzenbach, Switzerland, which resulted in the death of seven firemen who were trying to extinguish a fire in the garage. The failure developed first in one column and then propagated to a large part of the structure (Fig. 1(c)). The occurrence of progressive collapse initiated by a punching shear failure is neither rare nor limited to Switzerland and has occurred all over the world..$^{2-6}$

These structural collapses were motivated by various causes: deficiencies in design, shortcomings of design rules based on empirical formulas, ${ }^{7}$ errors during execution, and even unexpected actions. The structural safety in these cases should not be compromised, or at least the damages should be limited and proportional to such causes. This philosophy of design has inspired recent codes in Europe and America—for instance, EN $1990^{8}$ (Clause 2.1(4)P), which explicitly proposes that a structure has to be "designed and executed in such a way that it will not be damaged by events such as: explosion, impact and the consequences of human (a)

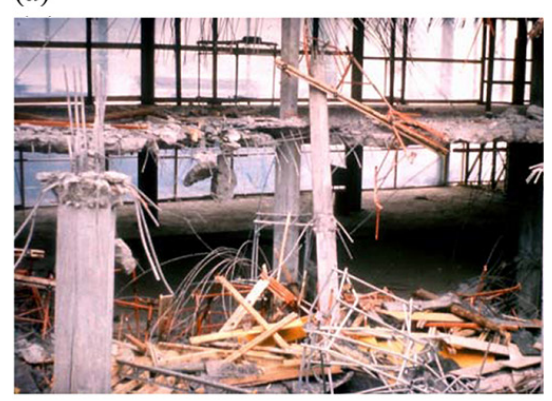

(b)

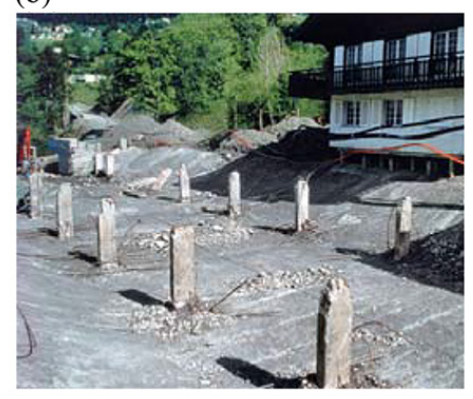

(c)

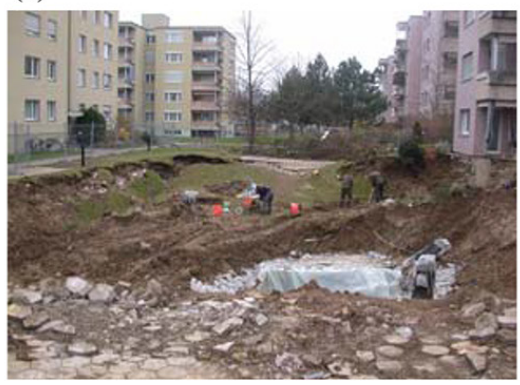

Fig. 1-Structural collapses due to punching shear failures in Switzerland: (a) shopping center, Serfontana, 1970s (photo courtesy of M. Ladner); (b) underground parking garage, Bluche, 1981 (photo courtesy of R. Suter); and (c) underground parking garage, Gretzenbach, 2004 (photo courtesy of A. Muttoni).

errors, to an extent disproportionate to the original cause." Brittle punching shear failures can, however, lead to disproportionate damage. ${ }^{7,9}$ Such brittle failures after small deformations typically develop for members without transverse reinforcement and for moderate-to-high flexural reinforce-

ACI Structural Journal, V. 110, No. 5, September-October 2013

MS No. S-2011-307 received October 5, 2011, and reviewed under Institute publication policies. Copyright (C) 2013, American Concrete Institute. All rights reserved, including the making of copies unless permission is obtained from the copyright proprietors. Pertinent discussion including author's closure, if any, will be published in the July-August 2014 ACI Structural Journal if the discussion is received by March 1, 2014. 
Miguel Fernández Ruiz is Lecturer and Research Scientist at Ecole Polytechnique Fédérale de Lausanne (EPFL), Lausanne, Switzerland. His research interests include the serviceability behavior of structures, bond, shear and punching shear, and the modeling of structural concrete using stress fields.

Yaser Mirzaei is a Structural Engineer at WSP Cantor Seinuk, New York. He received his PhD from EPFL in 2010. His research interests include shear and punching shear.

ACI member Aurelio Muttoni is Professor and Head of the Structural Concrete Laboratory at EPFL. He received the ACI Chester Paul Siess Award for Excellence in Structural Research in 2010. His research interests include the theoretical bases of the design of reinforced concrete structures, shear and punching shear, fiber-reinforced high-strength concrete, soil-structure interaction, and the conceptual design of bridges.

(a)

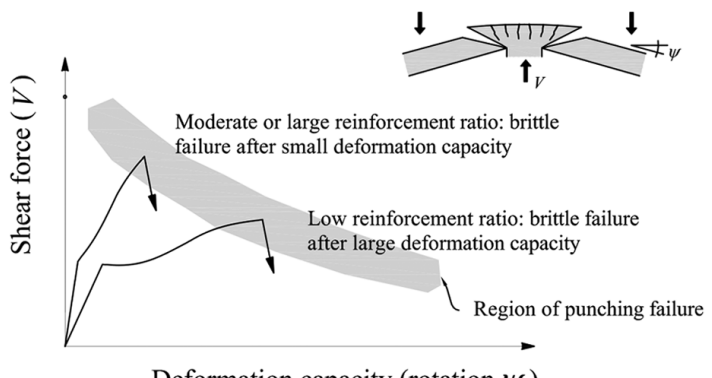

(b)

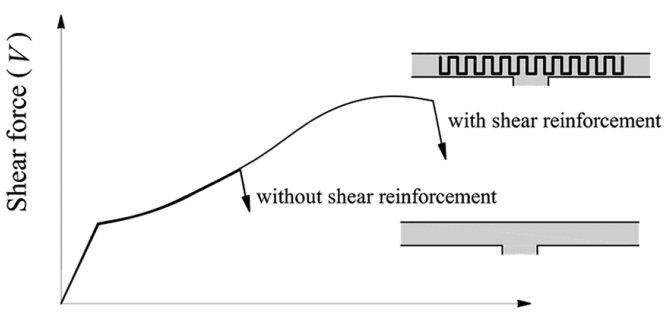

Deformation capacity (rotation $\psi$ )

(c)

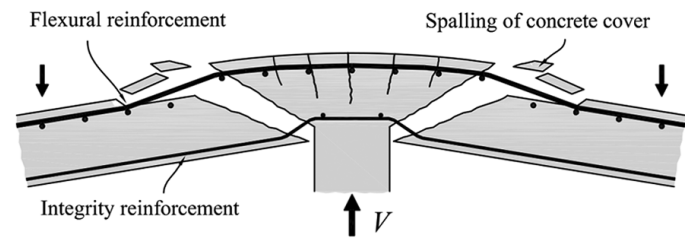

Fig. 2-Behavior of flat slab failing in punching shear: (a) brittle and ductile failures depending on amount of flexural reinforcement; (b) brittle and ductile failures for members without and with shear reinforcement; and (c) activation of flexural and integrity reinforcement after punching shear failure.

ment ratios over column (refer to Fig. 2(a)). This corresponds to most cases in practice and makes these structures rather sensitive to the effect of imposed deformations as shrinkage, differential settlements, or thermal deformations due to fire.

In the first complete draft of Model Code $2010,{ }^{10}$ robustness of flat slabs with respect to punching shear failures is ensured by providing sufficient deformation capacity to flat slabs. This allows redistribution of internal forces after punching of a column and avoids punching to propagate to adjacent columns. Sufficient deformation capacity can be ensured by means of sufficiently low flexural reinforcement ratios (yet larger than the minimum flexural reinforcement amount) to ensure that flexural strength is governing (refer to Fig. 2(a)) or by placing ordinary punching shear reinforcement ${ }^{9,11}$ (refer to Fig. 2(b)). If any of these measures is not fulfilled, integrity reinforcement is required according to
Model Code 2010. ${ }^{10}$ Such reinforcement (often named "compression reinforcement" in North America) typically consists of a straight bar passing above the supported area in the compression side (soffit) of the slab (refer to Fig. 2(c)). When a slab punches and the support area penetrates into the slab, the integrity bars get deformed, providing shear support to the slab due to dowelling action and membrane effect of the integrity bars. Also, the flexural reinforcement can potentially contribute to the post-punching shear strength (Fig. 2(c)). However, cover spalling develops after punching and severely reduces this contribution. The post-punching shear strength of the integrity reinforcement is, in general, activated for large deformations, which has implications in the redistribution of inner forces. ${ }^{6,12}$ A particular case of integrity reinforcement is that of bent-up bars (which were already extensively used for first reinforced concrete structures for development of the flexural reinforcement) that can also be considered effective integrity reinforcement, provided that they are properly developed in the compression side of the slab. Their use is particularly encouraged because they can be activated for smaller displacements and they also contribute to the punching shear strength in an effective manner. ${ }^{13,14}$

Some research has been performed on the topic of postpunching behavior of flat slabs. This research, however, is not as systematic and extensive as performed on other topics related to punching shear. Regan et al. ${ }^{15}$ investigated the effect of integrity reinforcement on the post-punching behavior by testing $100 \mathrm{~mm}$ (3.93 in.) thick slabs, and on that basis they proposed a design model. The approach followed by of Regan et al. ${ }^{15}$ (based on the works of Rasmussen ${ }^{16}$ ) considered the influence of the bar diameter, the yield strength of the integrity reinforcement, and the compressive strength of concrete. Experimental testing was later followed by McPeake ${ }^{17}$ and by Georgopoulos, ${ }^{18}$ who proposed a design method accounting for the reinforcement and concrete strengths. Mitchell and Cook ${ }^{19}$ investigated the role of flexural reinforcement on the post-punching strength. An extensive experimental campaign was carried out by Melo $^{6}$ and Melo and Regan ${ }^{12}$ accounting for the role of the anchorage of the flexural reinforcement. Other than the post-punching contribution of straight bars, research on the influence of bent-up bars in combination with cages of stirrups has been conducted by Broms. ${ }^{13,20}$ Additionally, some studies have been performed on the beneficial influence of post-tensioning tendons on the post-punching behavior. ${ }^{21-24}$

In this paper, the results of experimental and theoretical research on the post-punching behavior of slab-column joints performed by the authors are investigated. An extensive test series on 20 specimens (125 mm [4.92 in.] thick) was performed. The results are investigated on the basis of the various contributions to the post-punching shear strength (top and bottom reinforcement and bent-up bars, if applicable) to develop a rational model to predict post-punching strength of slab-column connections.

\section{RESEARCH SIGNIFICANCE}

The robustness of structures ensures that local failures due to unexpected actions or deficiencies during design or construction do not propagate to other members, leading to the collapse of the entire structure. In flat slabs, where brittle punching shear failures around columns may occur, robustness is, in most cases, ensured by placing integrity reinforcement over columns, providing post-punching strength and deformation capacity. The role and effective- 
(a)
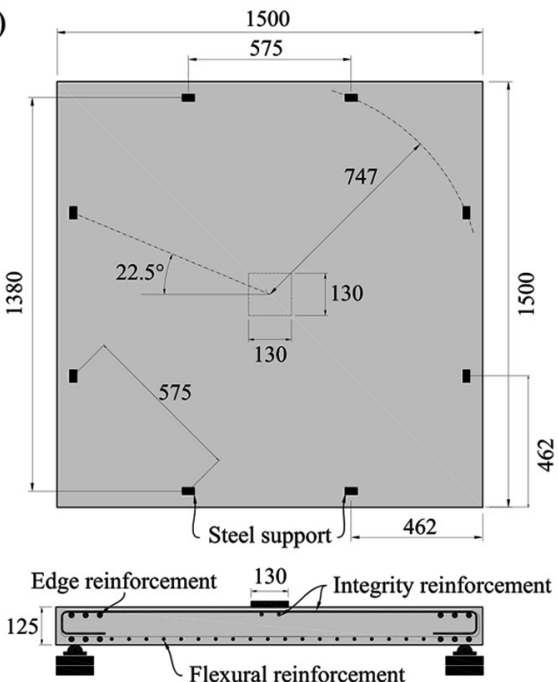

(b)

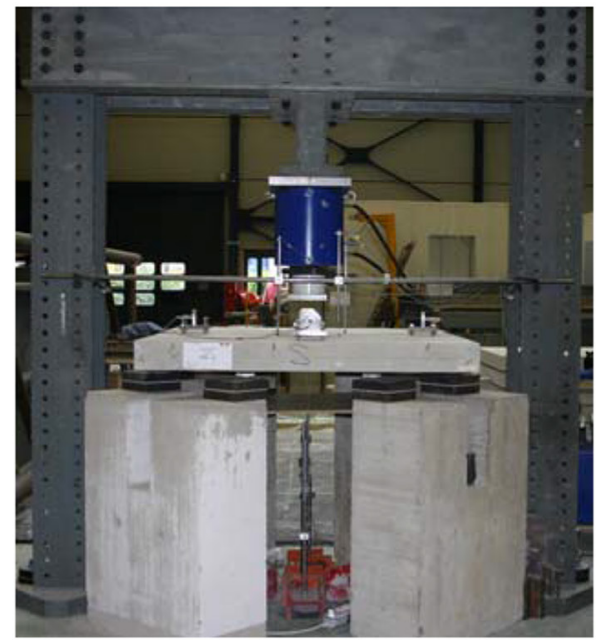

Fig. 3-Specimen and testing frame: (a) plan view and dimensions of specimens; and (b) testing frame. (Note: Dimensions in $\mathrm{mm} ; 1 \mathrm{~mm}=0.0394 \mathrm{in}$.)

ness of this reinforcement, however, is poorly addressed in the scientific literature, with little experimental data available. In this paper, a systematic test series is presented, allowing a clear understanding of the role of the various mechanical parameters and leading to a simple and accurate design model.

\section{EXPERIMENTAL CAMPAIGN Specimens and test series}

A total of 20 specimens were tested in four series. All specimens presented the same dimensions in plan (1500 x $1500 \mathrm{~mm}$ [59 x $59 \mathrm{in}]$.$) with a thickness of 125 \mathrm{~mm}$ (4.92 in.). The specimens were loaded through a stiff steel plate of $130 \times 130 \mathrm{~mm}(5.12 \times 5.12 \mathrm{in}$.) that simulated the support of the flat slab and where the punching cone developed. The specimens were supported at a radius of $747 \mathrm{~mm}$ (29.4 in.) on eight steel plates with polytetrafluoroethylene (PTFE) layers that allowed sliding and rotation of the specimen over supports. Accounting for the fact that the line of contraflexure of radial bending moments is located at approximately 0.22 times the span length for regular flat slabs, the specimens represented the support region of a flat slab with an equivalent slenderness (ratio between the thickness of the slab and its span length) of $1 / 27$. Figure 3 provides a plan view detailing the position of the load and supports.

The first series (six tests) had no integrity reinforcement and investigated the effects of flexural reinforcement and reinforcement amount ( $\rho$ ranging between 0.25 and $1.41 \%)$ on the post-punching strength. The amount of flexural reinforcement was kept constant $(\rho \approx 0.82 \%)$ for the rest of the test series. The role of an integrity reinforcement composed of well-anchored straight bars was investigated on the second series through six tests, where the amount of integrity reinforcement and the properties of the steel used for the integrity bars were varied. The third series (four tests) investigated the behavior of bent-up bars. Finally, the fourth series (four tests) investigated the role of anchorage and development length of the flexural reinforcement on the post-punching strength. Table 1 presents the main mechanical properties of the specimens.

Concrete cover was kept constant and equal to $15 \mathrm{~mm}$ (0.59 in.) for all specimens. Reinforcement was arranged for
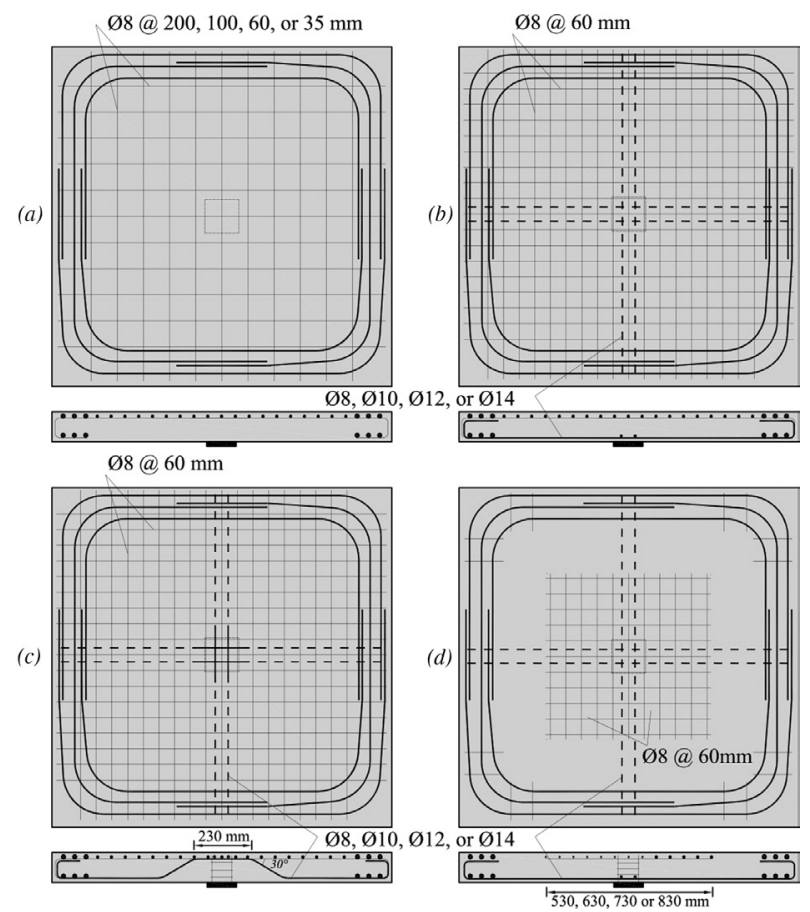

Fig. 4-Reinforcement layout: (a) PM1 to PM4, PM23, PM24; (b) PM9 to PM12, PM21, PM22; (c) PM17 to PM20; and (d) PM25 to PM28. (Note: $1 \mathrm{~mm}=0.0394 \mathrm{in}$.)

all specimens in orthogonal directions; details are given in Fig. 4. Flexural reinforcement was provided by using bars of $8 \mathrm{~mm}$ (0.32 in.) diameter, where its spacing was varied to provide the various flexural reinforcement ratios of the first test series (refer to Fig. 4(a)). For the rest of the specimens, the spacing of this reinforcement was constant and equal to $60 \mathrm{~mm}$ (2.36 in.). For the fourth test series (aiming at investigating the influence of anchorage of flexural reinforcement near the support region), the length of the flexural reinforcement varied: $530 \mathrm{~mm}$ (20.8 in.) for Specimen PM25, 
Table 1-Mechanical properties of tested specimens and main experimental results

\begin{tabular}{|c|c|c|c|c|c|c|c|c|c|c|c|}
\hline Series & Test & $f_{c}, \mathrm{MPa}$ & $d, \mathrm{~mm}$ & \multicolumn{4}{|c|}{ Flexural reinforcement } & \multicolumn{4}{|c|}{ Integrity reinforcement } \\
\hline 1 & PM1 & 36.6 & 102 & 0.25 & 601 & 664 & 7.39 & - & - & - & - \\
\hline 1 & PM2 & 36.5 & 102 & 0.49 & 601 & 664 & 7.39 & - & - & - & - \\
\hline 1 & PM3 & 37.8 & 102 & 0.82 & 601 & 664 & 7.39 & - & - & - & - \\
\hline 1 & PM4 & 36.8 & 102 & 1.41 & 601 & 664 & 7.39 & - & - & - & - \\
\hline 1 & $\mathrm{PM} 24$ & 40.4 & 97 & 0.86 & 625 & 641 & 6.07 & - & - & - & - \\
\hline 2 & PM9 & 31.0 & 102 & 0.82 & 601 & 664 & 7.39 & $4 \varnothing 8$ & 616 & 680 & 7.4 \\
\hline 2 & PM10 & 31.1 & 102 & 0.82 & 601 & 664 & 7.39 & $4 \varnothing 10$ & 560 & 599 & 7.9 \\
\hline 2 & PM11 & 32.3 & 102 & 0.82 & 601 & 664 & 7.39 & $4 \varnothing 12$ & 548 & 625 & $10.5^{*}$ \\
\hline 3 & PM17 & 39.7 & 102 & 0.82 & 625 & 641 & 6.07 & $4 \varnothing 8$ & 625 & 641 & 6.1 \\
\hline 3 & PM18 & 39.8 & 95 & 0.88 & 625 & 641 & 6.07 & $4 \varnothing 10$ & 605 & 658 & 7.8 \\
\hline 3 & PM19 & 39.9 & 99 & 0.85 & 625 & 641 & 6.07 & $4 \varnothing 12$ & 559 & 618 & 7.9 \\
\hline 3 & PM20 & 40.0 & 102 & 0.82 & 625 & 641 & 6.07 & $4 \varnothing 14$ & 578 & 695 & $12.0^{*}$ \\
\hline 4 & PM25 & 40.4 & 98 & 0.85 & 625 & 641 & 6.07 & $4 \varnothing 8$ & 625 & 641 & 6.1 \\
\hline 4 & PM26 & 40.3 & 101 & 0.83 & 625 & 641 & 6.07 & $4 \varnothing 10$ & 605 & 658 & 7.8 \\
\hline 4 & PM27 & 40.3 & 104 & 0.81 & 625 & 641 & 6.07 & $4 \varnothing 12$ & 559 & 618 & 7.9 \\
\hline 4 & PM28 & 40.3 & 99 & 0.85 & 625 & 641 & 6.07 & $4 \varnothing 14$ & 578 & 695 & $12.0^{*}$ \\
\hline
\end{tabular}

*All reinforcement bars are cold-worked except those marked with asterisk.

Notes: $1 \mathrm{~mm}=0.0394$ in.; $1 \mathrm{MPa}=145$ psi.

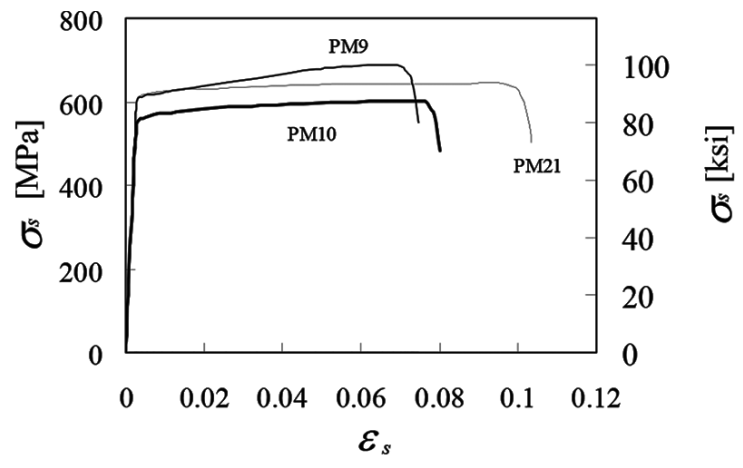

(a)

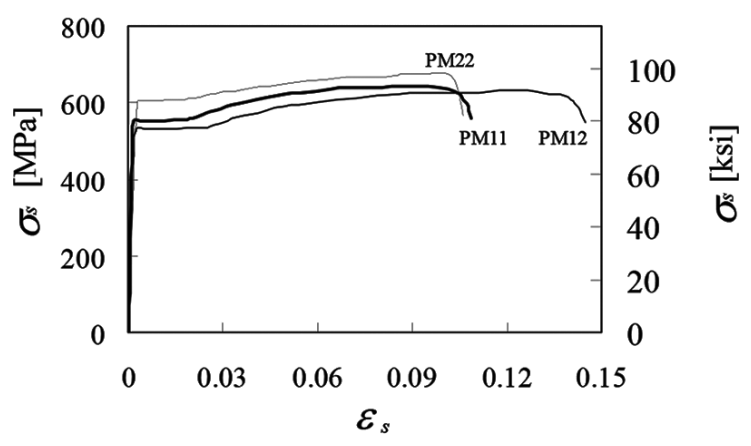

(b)

Fig. 5-Typical stress-strain relationships of integrity reinforcement: (a) cold-worked; and (b) hot-rolled.
$630 \mathrm{~mm}$ (24.8 in.) for Specimen PM26, $730 \mathrm{~mm}$ (28.7 in.) for Specimen PM27, and $830 \mathrm{~mm}$ (32.7 in.) for Specimen PM28.

\section{Material properties}

The specimens were cast with normal-strength concrete. The maximum aggregate size was $16 \mathrm{~mm}(0.63 \mathrm{in}$.). Their compressive strengths at the time of testing ranged between 31.0 and $40.4 \mathrm{MPa}$ (4500 and $6000 \mathrm{psi}$ ). More details are given in Table 1.

Flexural reinforcement was composed of cold-worked $8 \mathrm{~mm}$ (0.32 in.) diameter bars. This reinforcement did not present a well-defined yield plateau and the yield strength ranged between 641 and $664 \mathrm{MPa}$ (93 and $96 \mathrm{ksi}$ ) (determined as the stress leading to a residual plastic strain after unloading equal to $0.2 \%$ ). The diameter of the integrity reinforcement varied between 8 and $14 \mathrm{~mm}(0.32$ and $0.55 \mathrm{in}$.). It was coldworked (Fig. 5(a)) for diameters up to $10 \mathrm{~mm}$ (0.40 in.) and hot-rolled (with yield plateau and large strains at tension failure; refer to Fig. 5(b)) for bars with a diameter of $14 \mathrm{~mm}$ (0.55 in.). For $12 \mathrm{~mm}$ (0.47 in.) diameter bars, hot-rolled (Specimen PM11) and cold-worked (Specimen PM21) bars were used to compare the differences in behavior. Details for reinforcement type used in each specimen are given in Table 1.

\section{Development of tests}

All tests were performed following the same procedure. Load was applied downward in the middle of the specimen through a steel plate (refer to Fig. 3). The flexural reinforcement was thus placed on the bottom side of the specimen and the integrity reinforcement composed of straight bars 
(a)

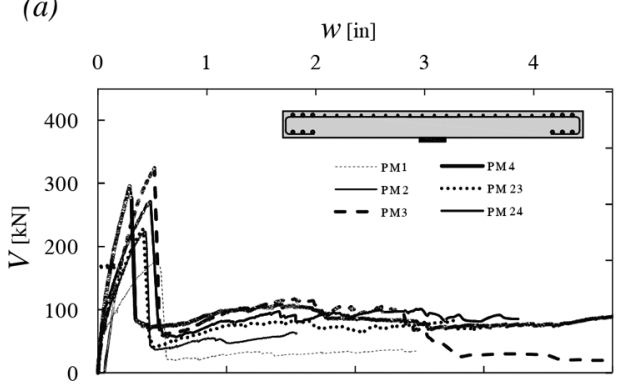

(c)

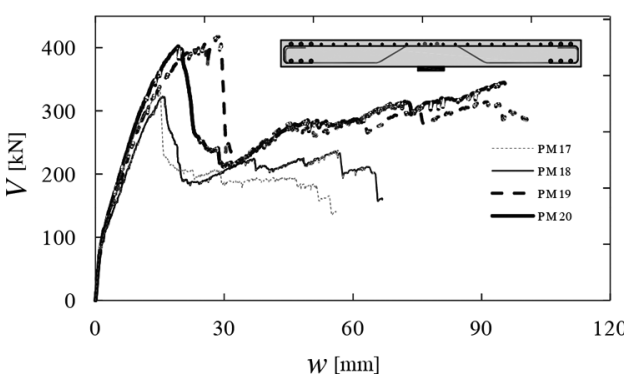

(b)

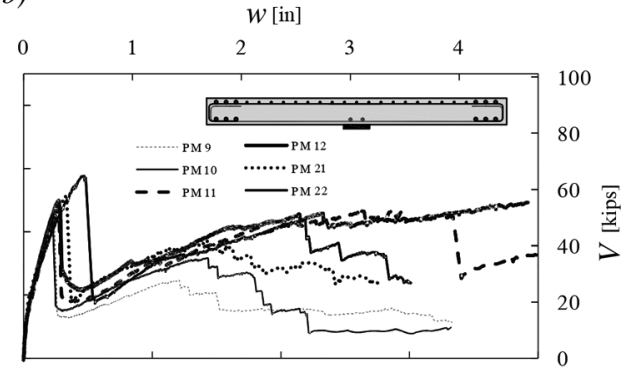

(d)

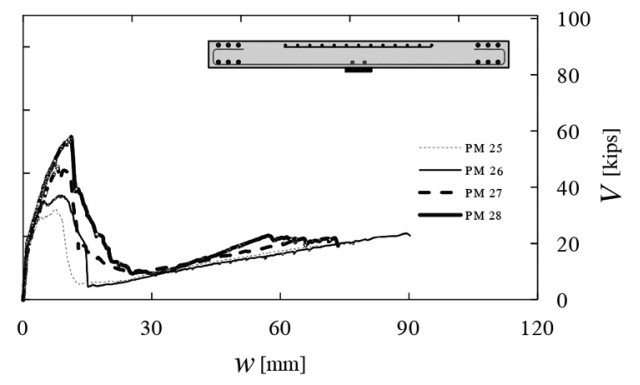

Fig. 6-Load-deflection (between applied loads and support plate) curves for all specimens: (a) Test Series 1 (no integrity reinforcement); (b) Test Series 2 (straight integrity reinforcement); (c) Test Series 3 (bent-up bars); and (d) Test Series 4 (short-length flexural reinforcement). (Note: Dimensions in $\mathrm{mm} ; 1 \mathrm{~mm}=0.0394 \mathrm{in}$.)

was placed on the top side of it. Load was monotonically increased until the specimens punched. During this first stage (approximately 30 minutes), the load was applied under controlled displacement to capture the decrease on the applied load after punching. Thereafter, the imposed displacement was applied at the same rate than that prior to punching. In this stage, the applied load could be increased up to a maximum value limited by rupture of the integrity reinforcement or by extensive degradation of concrete. The tests were stopped after such post-punching strength was reached. In some cases, however, the tests were stopped after large deformations of the specimens (with deflections larger than $100 \mathrm{~mm}$ [3.92 in.]), or when significant degradation of the concrete inside the punching cone region occurred.

\section{Measurements}

Continuous readings were provided for both the applied load, and rotations and deflections of the slab. Load was recorded through a load cell placed between the hydraulic jack and the specimen. Deflections were measured by means of linear variable differential transformers (LVDTs) placed on the top and on the bottom of the specimen. Four inclinometers where also placed at the edges of the specimen. For selected specimens, measurements of the penetration of the punch were also provided.

\section{Main experimental results}

The load-deflection curves for the different specimens are shown in Fig. 6. Details of the measured strength $V_{p}$, the deflections at punching $w_{p}$, the maximum recorded strength after punching $V_{p p}$, and its corresponding deflection $w_{p p}$ are given in Table 2. The following observations can be made:

(a) The first series (PM1 to PM4, PM23, and PM24; refer to Fig. 6(a)) shows that well-anchored flexural reinforcement is activated after punching of the slab. Its contribution is rather constant with increasing penetration of the punch,
Table 2-Main experimental results of tests

\begin{tabular}{|c|c|c|c|c|}
\hline \multirow[b]{2}{*}{ Test } & \multicolumn{4}{|c|}{ Measured } \\
\hline & $V_{p}, \mathrm{kN}$ & $w_{p}, \mathrm{~mm}$ & $V_{p p}, \mathrm{kN}$ & $w_{p p}, \mathrm{~mm}$ \\
\hline PM1 & 176 & 14 & 37 & 71 \\
\hline PM2 & 224 & 11 & 66 & 53 \\
\hline PM3 & 324 & 13 & 117 & 45 \\
\hline PM4 & 295 & 7 & 108 & 43 \\
\hline PM23 & 227 & 10 & 82 & 83 \\
\hline PM24 & 272 & 12 & 101 & 74 \\
\hline PM9 & 224 & 7 & 123 & 36 \\
\hline PM10 & 228 & 7 & 159 & 43 \\
\hline PM11 & 241 & 8 & 237 & 86 \\
\hline PM12 & 249 & 8 & 245 & 117 \\
\hline PM21 & 256 & 10 & 185 & 43 \\
\hline PM22 & 288 & 14 & 219 & 65 \\
\hline PM17 & 329 & 15 & 194 & 50 \\
\hline PM18 & 323 & 16 & 237 & 57 \\
\hline PM19 & 417 & 29 & 315 & 90 \\
\hline PM20 & 402 & 19 & 345 & 95 \\
\hline PM25 & 143 & 8 & 85 & 70 \\
\hline PM26 & 165 & 9 & 105 & 89 \\
\hline PM27 & 211 & 8 & 94 & 64 \\
\hline PM28 & 258 & 11 & 101 & 57 \\
\hline
\end{tabular}

Notes: $1 \mathrm{~mm}=0.0394$ in.; $1 \mathrm{kN}=0.225$ kip.

but for the tested specimens, it remains smaller than $35 \%$ of the punching load in all cases .

(b) The second series (Fig. 6(b)) shows a significant increase on the post-punching strength when straight bars 
in the compression zone are used as integrity reinforcement (Specimens PM9 to PM12, PM21, and PM22). For specimens with the largest bar diameters (12 and $14 \mathrm{~mm} \mathrm{[0.47} \mathrm{and}$ 0.55 in.]), the post-punching strength was similar to the punching strength. Large penetrations of the punch (of the same magnitude as the effective depth of the slab), however, were required to activate such strengths. Comparing Specimens PM9 and PM10 to Specimens PM21 and PM22, it can be noted that the maximum strain of the reinforcement steel at tensile rupture plays a significant role on the post-punching strength. For instance, Specimen PM22 (where the tensile strain at failure was $\varepsilon_{s u}=10.3 \%$ for the integrity reinforcement) reached a post-punching strength of $219 \mathrm{kN}$ (49.0 kip), whereas Specimen PM10 (with similar characteristics but $\varepsilon_{s u}=7.9 \%$ ) reached only $159 \mathrm{kN}$ (35.6 kip). A similar trend was also observed for Specimens PM21 and PM9.

(c) Bent-up bars (Fig. 6(c)) are an efficient way to increase the punching ${ }^{14}$ and post-punching strength. This can be observed in Specimens PM17 to PM20, where the highest punching and post-punching strengths of the investigated series are obtained for corresponding diameter of the integrity reinforcement.

(d) With respect to the influence of the development conditions of the flexural reinforcement, the results of the fourth test series (Specimens PM25 to PM28), when compared to the reference specimens (PM9 to PM12), indicate that significant reductions on the punching and post-punching strength were recorded. These tests, however, were stopped prior to reaching the potential maximum post-punching load due to a significant risk of falling down the punching cone (very large concrete cracks and spalling of large portions of the specimen). In addition, for members with a short length of flexural reinforcement, the punching shear strength also decreases. This can be observed for Specimens PM25 to PM28 with relatively short flexural reinforcement, where the reduction of the punching load is correlated to the length of the flexural reinforcement (this influence will be discussed later). This is due to the fact that the flexural reinforcement is cut off in the shear-critical region, leading to a localization of the cracks and, thus, to a larger opening the width of the critical shear crack, leading to punching failure. ${ }^{7,11}$

\section{CALCULATION OF POST-PUNCHING SHEAR STRENGTH}

The observed experimental behaviors lead to the following findings:

- Flexural reinforcement is capable of developing a limited post-punching strength. This contribution is rather stable and activated right after punching, provided that the flexural reinforcement is properly anchored.

- Integrity reinforcement composed of straight bars over the support is effective to increase the post-punching strength, provided that it is suitably developed. Its activation, however, requires significant punch penetration and its efficiency is significantly dependent on the deformation capacity of the reinforcement (steel strain at rupture).

- Integrity reinforcement composed of bent-up bars is the most effective way tested for providing post-punching strength. Additionally, the punching strength is also increased and the activation of the post-punching strength requires smaller punch penetration than for straight bars.

In a general manner (Fig. 2(c)), the post-punching resistance $V_{R, p p}$ depends on the contribution of the flexural reinforcement $V_{R, p p, b e n d}$ and the integrity reinforcement $V_{R, p p \text {,int }}$

$$
V_{R, p p}=V_{R, p p, b e n d}+V_{R, p p, i n t}
$$

This is due to the fact that this strength is activated for relatively large displacements and the punching cone is thus separated from the rest of the slab (no forces are carried by concrete friction). The role of the two components of Eq. (1) is investigated in detail in the following.

\section{Contribution of flexural reinforcement}

As shown by the first test series, flexural reinforcement contributes to the post-punching strength of slabs. This contribution is almost fully activated after punching failure and remains fairly constant thereafter. Contrary to the integrity reinforcement, where bars failed in tension by steel rupture, no ruptures in tension of the flexural reinforcement were reported in the tests performed in this paper. This indicates that the strains developed in the steel were moderate (lower in any case to the ultimate strain). The contribution of the flexural reinforcement was, on the contrary, governed by the number of bars activated at failure and by their dowelling strength (due to spalling of the concrete cover; refer to Fig. 2(c)). The maximum post-punching strength can thus be calculated as

$$
V_{R, p p, \text { bend }}=n_{b, \text { bend }} \cdot f_{c t} \cdot b_{e f} \cdot \ell_{e f}
$$

where $n_{b, b e n d}$ is the number of sections of the flexural bars activated during the post-punching phase (Fig. 7(a) to (c)); $f_{c t}$ is tensile strength of concrete $\left(f_{c t} \cong 0.5 \sqrt{ } f_{c}\right.$ [MPa] $\left[f_{c t} \cong\right.$ $6 \sqrt{ } f_{c}$ (psi)]; and $b_{e f}$ and $\ell_{e f}$ are the effective width and length of concrete where the tensile strength develops for each bar, respectively. The meaning of the various parameters is further clarified in Fig. 7(d) and (e).

The effective width where the tensile strength develops, $b_{e f}$, accounts for the fact that the distribution of tensile stresses in the concrete is not constant; refer to Fig. 7(e). As demonstrated for spalling failures, ${ }^{25}$ the value of $b_{e f}$ depends on the concrete cover $c_{b}$, diameter of the reinforcing bars $d_{b}$, and on their spacing $s_{b}$, and can be evaluated as ${ }^{25}$

$$
b_{e f}=\min \left(s_{b}-d_{b} ; 6 d_{b} ; 4 c_{b}\right)
$$

The effective length $\ell_{e f}$ determines the length where the pullout force is transferred to the concrete (Fig. 7(d)). Experimental and analytical studies of this phenomenon ${ }^{26}$ show that the effective length is correlated to the bar diameter. The results of the tests presented in this paper show that this hypothesis leads to accurate results and that adopting a constant value for this parameter is sufficient for design purposes. Thus, the authors propose to estimate the effective length as

$$
\ell_{e f f}=2 d_{b}
$$

With respect to the number of flexural bars activated during the post-punching phase, the rather different behavior of the flexural top and bottom layer should be noted (refer to Fig. 7(a) to (c)). The bars on the flexural bottom layer are only activated if they are intersected by the punching cone over the supported surface (Fig. 7(c)). However, the bars on the top layer are activated not only by the punching cone but also by the bottom layer of reinforcement (Fig. 7(b)). Consequently, the number of activated bars at failure is larger than 
(a)

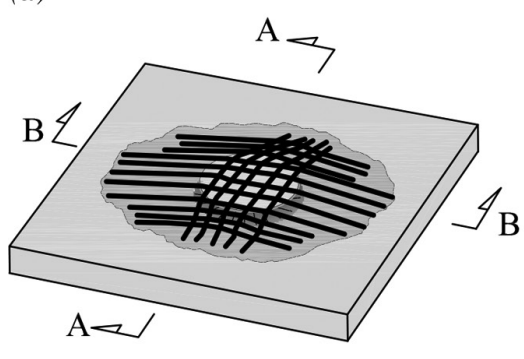

(d) (b)

A

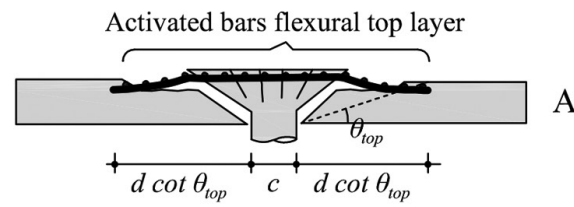

(c)

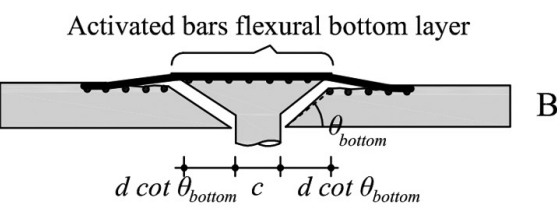

(e)

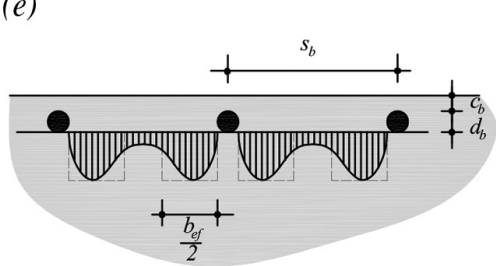

Fig. 7-Contribution of flexural reinforcement to post-punching strength: (a) activation of top and bottom layer of flexural reinforcement; (b) detail (section perpendicular to top layer); (c) detail (section perpendicular to bottom layer); (d) transfer of shear force by dowelling action to concrete, definition of effective length $\left(\ell_{\mathrm{ef}}\right)$; and (e) cross section, actual profile of stresses and definition of effective width $\mathrm{b}_{\mathrm{ef}}$.

those exclusively located over the punching cone. It can also be noted that considering a constant number of activated flexural bars in Eq. (2) leads to a constant contribution to the post-punching strength (independently of the column penetration), in agreement to the test results (Fig. 6(a)).

The number of sections activated (number of times the flexural reinforcement develops the dowelling action) can be calculated on this basis as

$$
n_{b, \text { bend }}=4 \cdot n_{a}=4 \cdot \frac{c+2 d \cot \theta}{s_{b}}
$$

where $n_{a}$ is the average number of activated flexural bars by the punching cone, which is multiplied by four to account for the cross sections crossed by the punching cone (each side of the bar in the two reinforcement directions). For calculation of $n_{a}$, Fig. 7(b) and (c) apply, where $c$ is the column size, $d$ is the effective depth of the slab, $\theta$ is the average angle where the flexural bars are activated $\left(\cot \theta=\left(\cot \theta_{\text {top }}+\cot \theta_{\text {bottom }}\right) / 2\right.$ (refer to Fig. 7(b) and (c)), and $s_{b}$ is spacing of the flexural reinforcement. As mentioned previously, activation of the top layer of the flexural reinforcement by the bottom layer allows one to account for an effective value of the inclination of the punching cone larger than the actual one. For design purposes, adopting a constant value $\cot \theta=2.8$ leads to fairly good predictions of the actual number of activated bars. This is justified in the comparison presented in Table 3 on the basis of Fig. 8 for Specimens PM1 to PM4 (without integrity reinforcement) with an average value of the measured-tocalculated ratio equal to 1.09 and a coefficient of variation (COV) of $8 \%$.

\section{Contribution of integrity reinforcement}

The model discussed in the following has been developed by the authors of this paper on the basis of References 6 and 12 , and is the design model currently adopted by fib Model Code $2010^{10}$ with respect to post-punching strength of slabs
Table 3-Activation of flexural bars after punching, and comparison between experimental results and theoretical model

\begin{tabular}{|c|c|c|c|c|c|}
\hline Specimen & $s_{b}, \mathrm{~mm}$ & $n_{t}$ & $n_{b}$ & $n_{a}$ & $\frac{n_{t}+n_{b}}{2 n_{a}}$ \\
\hline PM1 & 200 & 5 & 3 & 3.5 & 1.14 \\
\hline PM2 & 100 & 7 & 8 & 7.0 & 1.07 \\
\hline PM3 & 60 & 14 & 12 & 11.7 & 1.11 \\
\hline PM4 & 35 & 24 & 18 & 20.0 & 1.05 \\
\hline Average & & & & & 1.09 \\
\hline $\mathrm{COV}$ & & & & & 0.04 \\
\hline
\end{tabular}

Notes: $s_{b}$ is flexural reinforcement spacing; $n_{t}$ is activated bars on flexural top layer; $n_{b}$ is activated bars on flexural bottom layer; $n_{a}$ is calculated number of activated bars (according to Eq. (5)); $1 \mathrm{~mm}=0.0394$ in.

(improving the version proposed in first complete draft ${ }^{10}$ of this code).

The contribution of the integrity reinforcement at failure (bar rupture as observed during the tests) can be calculated by equilibrium conditions (Fig. 9(a)) as

$$
V_{R, p p, i n t}=n_{b, \text { int }} \cdot A_{s} \cdot f_{t} \cdot \sin \psi_{t}
$$

where $n_{b, \text { int }}$ is the number of sections of the integrity bars suitably developed and intersected by the failure surface (generally, only bars over the supported area are to be included); $A_{s}$ is the cross section of the integrity bars; $f_{t}$ is the tensile strength of the integrity reinforcement (referring to the maximum strength of the steel after plastic hardening); and $\psi_{t}$ is the average angle of the bars with respect to the plane of the slab.

The value for angle $\psi_{t}$ depends on a number of factors, such as the deformation capacity of the reinforcement (strain at steel tensile rupture), local failure of concrete outside the supported region (refer to Fig. 9(a)), stiffness 

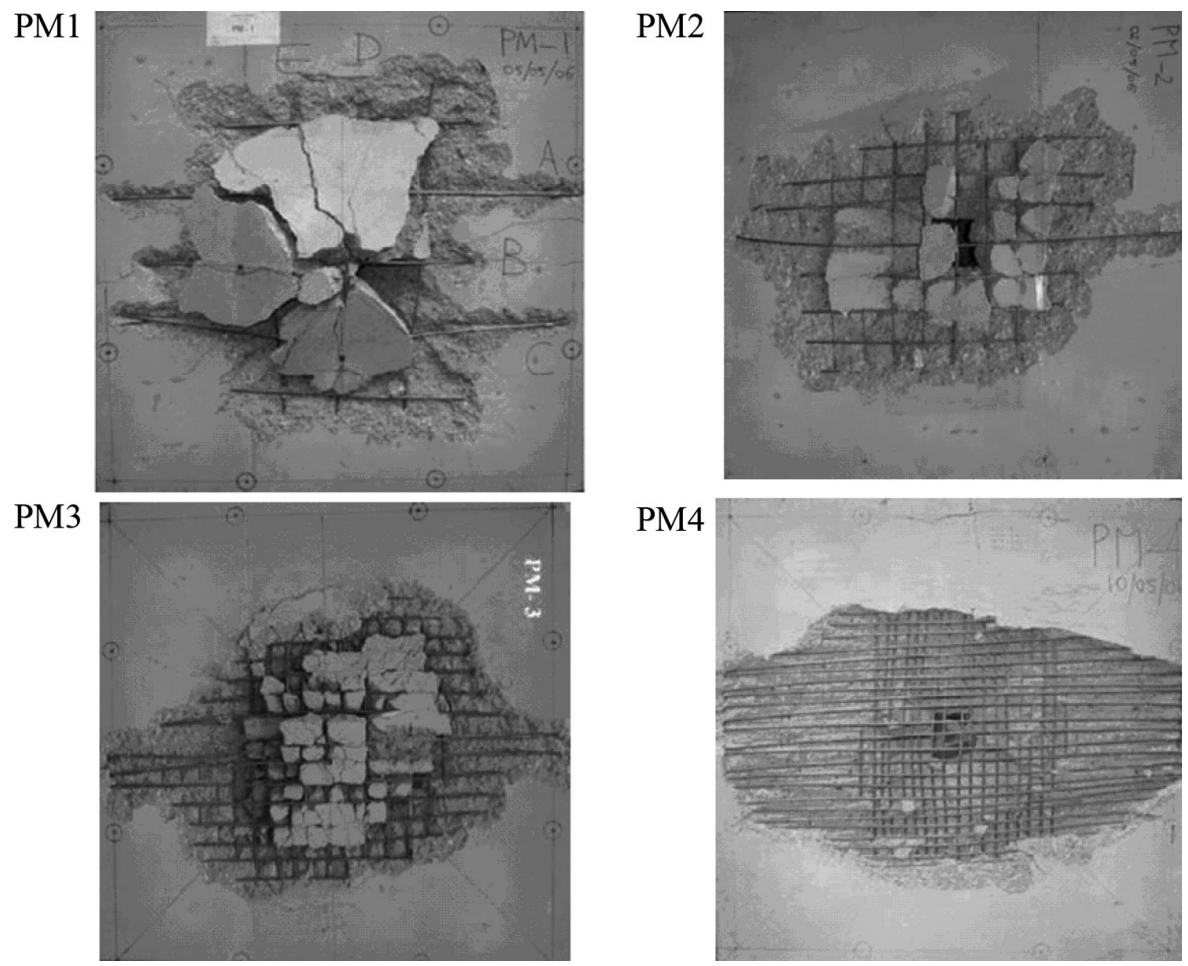

Fig. 8-Plan view of tested slabs PM1 to PM4 with detail of activated flexural bars during post-punching phase.

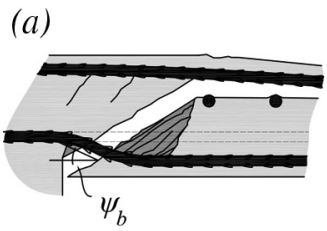

(c)

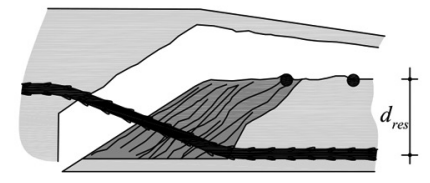

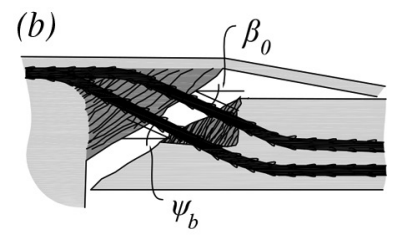

(d)

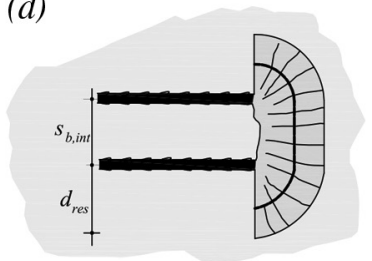

Fig. 9-Contribution of integrity reinforcement: (a) initially horizontal bars; (b) bent-up bars; (c) failure of concrete outside punching cone; and $(d)$ width of group of integrity bars and control perimeter.

of the supported area, and others. Experimental measurements, ${ }^{6}$ however, have shown that the value of this angle is fairly constant. This evidence has also been confirmed by the tests presented in this paper. Consequently, it is proposed to adopt, for practical purposes, a value $\psi_{t}=20$ degrees for cold-worked steel (for instance, corresponding to ductility Class B according to Model Code $2010,{ }^{10} \varepsilon_{\text {suk }} \geq 5 \%$ ) and $\psi_{t}=$ 25 degrees for hot-rolled bars (for instance, corresponding to ductility Class $\mathrm{C}$ according to Model Code $2010,{ }^{10} \varepsilon_{\text {suk }} \geq 7 \%$ ), which accounts for the dependency of the maximum rotation capacity of the integrity reinforcement on the ductility of the reinforcement ${ }^{27}$ (larger strain at tensile rupture for hot-rolled bars corresponding to a larger rotation capacity).

The strength that can be activated by the integrity reinforcement can nevertheless be limited by the strength of the

concrete where the integrity reinforcement is anchored outside the supported region (Fig. 9(c)). In this case, the maximum strength can be calculated assuming that the dowelling force of the bars equals the concrete pullout strength; thus ${ }^{12}$

$$
V_{R, p p, i n t} \leq f_{c t} \cdot A_{c, e f}
$$

where $f_{c t} \cong 0.5 \sqrt{ } f_{c}[\mathrm{MPa}]\left(f_{c t} \cong 6 \sqrt{ } f_{c}\right.$ [psi]) refers to the tensile strength of concrete. The effective concrete area $A_{c, e f}$ is calculated as

$$
A_{c, e f}=d_{r e s} \cdot b_{i n t}
$$

where $d_{\text {res }}$ is the residual effective depth of the slab (distance between centroids of flexural and integrity reinforcement layers (Fig. 9(c)), and $b_{\text {int }}$ is the control perimeter activated by the integrity reinforcement (Fig. 9(d)), whose value is proposed to be estimated as

$$
b_{\text {int }}=\Sigma\left(s_{b, \text { int }}+\frac{\pi}{2} d_{r e s}\right)
$$

In this equation, the sum refers to the groups of bars activated at the edge of the supported area (four groups in general for inner columns, accounting for the two sides of the two reinforcement directions) and $s_{b, i n t}$ is equal to the width of the group of bars in one direction; refer to Fig. 9(d) (similar consideration to that of Melo and Regan ${ }^{12}$ ).

It should be noted that, for activation of the integrity reinforcement, notable damage of concrete occurs both in the punching cone region and outside. Due to this reason, the number of flexural bars efficiently contributing to the post-punching shear strength has to be reduced with respect 
to members without integrity reinforcement. In accordance to the experiments presented in this paper, a constant value $\cot \beta=0.8$ is proposed as a safe and reasonable estimate for this parameter in case an integrity reinforcement is provided.

\section{Additional considerations for bent-up bars}

Previous design equations can also be applied to members with bent-up bars by applying the equations of the integrity reinforcement to the bent-up bars. The following considerations should nevertheless be accounted for:

- The angle of the integrity reinforcement $\psi_{b}$ can be adopted as $\psi_{b}=\beta_{b}\left(\geq 25\right.$ degrees), where $\beta_{b}$ refers to the angle of the bent-up bar with respect to the axis of the slab. Significant increases of the angle have not been observed in the performed tests (Fig. 10) due to the extreme damage developed in the punching cone region that eventually shifts the location of the bents of the bar (Fig. 9(b)).

- The activation of the bent-up bars as integrity reinforcement leads to pullout of the concrete between the bent-up bars and the flexural bars (Fig. 9(b)). Consequently, the pieces of the pulled-out concrete can activate a larger number of flexural bars than for straight integrity reinforcement (refer to Fig. 10). This can be accounted by considering a larger value of $\cot \theta=2.2$.

\section{Comparison to test results}

Table 4 compares the results obtained using the previously derived formulas for the tests presented in this paper (excluding Tests PM25 to PM28 that were stopped before the maximum post-punching strength was reached) as well as those from Melo and Regan ${ }^{12}$ and Broms. ${ }^{28}$ The results show a very good agreement in terms of the predicted failure load, with an average of the measured-to-calculated post-punching strength of 1.02 and a COV equal to $8.9 \%$. No scatter or particular trend is observed for the developed failure modes.

\section{DESIGN IMPLICATIONS}

The experimental results have shown a number of issues:

- Bending reinforcement is inefficient if insufficient anchorage is provided. This has a significant influence for the punching strength (refer to Fig. 11(a)) but also influences the post-punching strength of slabs. Tests PM25 to PM28 show that for short cutoff distances, the contribution of the flexural reinforcement to the post-punching strength can almost be neglected. For the rest of the specimens (perfect anchorage by means of a hook at the edge of the slab), the concrete cover was pulled out by the bending reinforcement up to a distance of approximately five to seven times the effective depth of the slab. This finding has also been made by Melo and Regan ${ }^{12}$ on the basis of test results. For practical applications, it should be explained that only when the bending reinforcement is anchored in the soffit of the slab (Fig. 11(b)) can such reinforcement be considered in the post-punching strength.

- An alternative way to enhance the post-punching behavior of the flexural reinforcement is to place shear reinforcement enclosing at least one of the flexural reinforcement layers (Fig. 11(c)). In this case, the activation of the flexural reinforcement is no longer controlled by the spalling of the concrete cover and leads to a similar behavior to the integrity reinforcement's behavior.

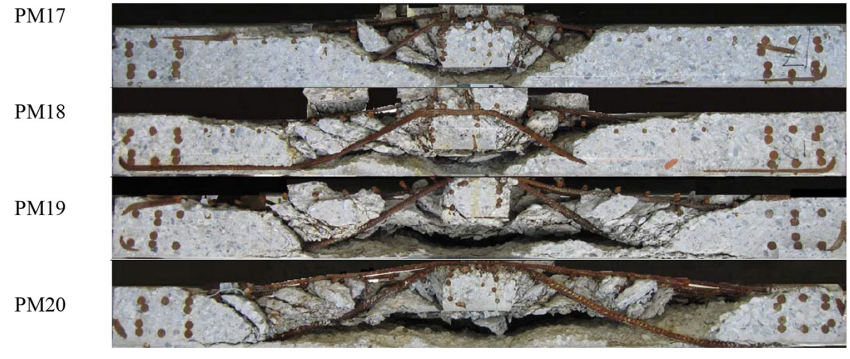

Fig. 10-Saw-cuts after post-punching regime of specimens with bent-up bars.

Table 4-Comparison of theoretical model to experimental results

\begin{tabular}{|c|c|c|c|c|c|c|}
\hline Test $^{\text {Ref }}$ & $\begin{array}{c}V_{R, p p, t e s t}, \\
\mathrm{kN}\end{array}$ & $\begin{array}{c}V_{R, p p, i n t}, \\
\mathrm{kN}\end{array}$ & $\begin{array}{c}V_{R, p p, \text { bend }} \\
\mathrm{kN}\end{array}$ & $\cot \theta$ & $\begin{array}{c}V_{R, p p, c a l c} \\
\mathrm{kN}\end{array}$ & $\frac{V_{R, p p, t e s t}}{V_{R, p p, c a l c}}$ \\
\hline PM1 & 33.4 & - & 32.6 & 2.8 & 32.6 & 1.03 \\
\hline PM2 & 66 & - & 65 & 2.8 & 65 & 1.01 \\
\hline PM3 & 117 & - & 111 & 2.8 & 111 & 1.06 \\
\hline PM4 & 108 & - & 105 & 2.8 & 105 & 1.03 \\
\hline PM23 & 82 & - & 108 & 2.8 & 108 & 0.76 \\
\hline PM24 & 101 & - & 110 & 2.8 & 110 & 0.92 \\
\hline PM9 & 123 & $94^{*}$ & 42 & 0.8 & 135 & 0.91 \\
\hline PM10 & 159 & $129^{*}$ & 42 & 0.8 & 171 & 0.93 \\
\hline PM11 & 237 & $201^{\dagger}$ & 43 & 0.8 & 244 & 0.97 \\
\hline PM12 & 245 & $202^{\dagger}$ & 43 & 0.8 & 245 & 1.00 \\
\hline PM21 & 185 & $109^{*}$ & 48 & 0.8 & 157 & 1.18 \\
\hline PM22 & 219 & $175^{*}$ & 47 & 0.8 & 222 & 0.99 \\
\hline PM17 & 194 & $129^{*}$ & 93 & 2.2 & 222 & 0.87 \\
\hline PM18 & 237 & $166^{\dagger}$ & 89 & 2.2 & 254 & 0.93 \\
\hline PM19 & 315 & $198^{\dagger}$ & 91 & 2.2 & 289 & 1.09 \\
\hline PM20 & 345 & $224^{\dagger}$ & 94 & 2.2 & 318 & 1.09 \\
\hline $6 \mathrm{ST}^{12}$ & 41 & $38^{*}$ & - & - & 38 & 1.07 \\
\hline $6 \mathrm{LG}^{12}$ & 41 & $38^{*}$ & - & - & 38 & 1.07 \\
\hline $8 \mathrm{ST}^{12}$ & 57 & $55^{*}$ & - & - & 55 & 1.04 \\
\hline $8 \mathrm{LG}^{12}$ & 57 & $55^{*}$ & - & - & 55 & 1.04 \\
\hline $10 \mathrm{ST}^{12}$ & 82 & $82^{*}$ & - & - & 82 & 1.00 \\
\hline $10 \mathrm{LG}^{12}$ & 90 & $82^{*}$ & - & - & 82 & 1.09 \\
\hline $12 \mathrm{LG}^{12}$ & 123 & $124^{*}$ & - & - & 124 & 0.99 \\
\hline $2^{12}$ & 64 & $61^{\dagger}$ & $0^{\ddagger}$ & - & 61 & 1.05 \\
\hline $3^{12}$ & 81 & $68^{\dagger}$ & $0^{\ddagger}$ & - & 68 & 1.19 \\
\hline $4^{12}$ & 66 & $64^{\dagger}$ & $0^{\ddagger}$ & - & 64 & 1.03 \\
\hline $5^{12}$ & 65 & $62^{\dagger}$ & $0^{\ddagger}$ & - & 62 & 1.04 \\
\hline $9^{28}$ & 230 & $113^{*}$ & 96 & 2.2 & 208 & 1.10 \\
\hline $9 a^{28}$ & 220 & $113^{*}$ & 85 & 2.2 & 197 & 1.12 \\
\hline $11^{28}$ & 445 & $430^{*}$ & 61 & 2.2 & 491 & 0.91 \\
\hline & & & \multicolumn{2}{|c|}{ Average } & & 1.02 \\
\hline & & & \multicolumn{2}{|c|}{$\mathrm{COV}, \%$} & & 8.9 \\
\hline
\end{tabular}

${ }^{*}$ Failure by rupture of integrity reinforcement.

'Failure by crushing outside punching cone.

*Insufficient anchorage conditions.

Note: $1 \mathrm{kN}=0.225 \mathrm{kip}$. 
(a)

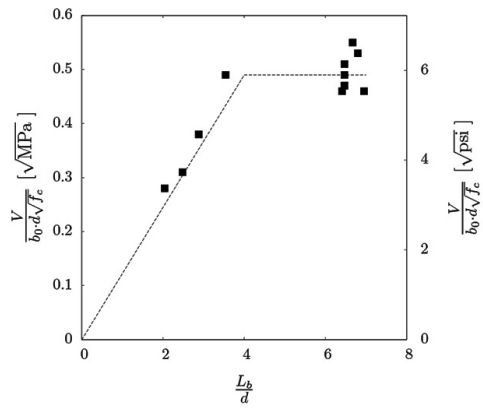

(b)

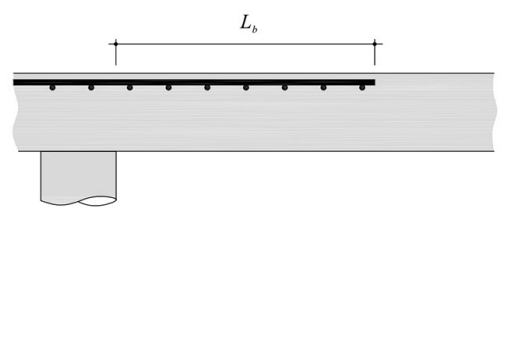

(c)
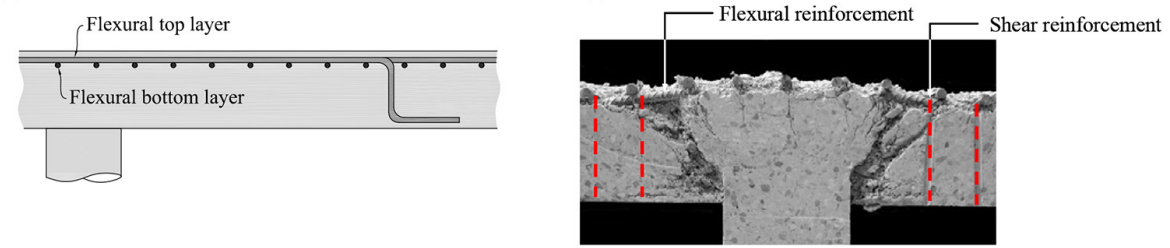

Fig. 11-Design recommendations: (a) influence of cutofflength offlexural reinforcement on punching strength; results of tests presented in this paper (Specimens PM21 to PM24 along linear decreasing branch); (b) perfect anchorage conditions for bending reinforcement; and $(c)$ enhanced activation of straight flexural reinforcement by placing of shear reinforcement.

- Integrity reinforcement composed of straight bars may require relatively large diameters and reinforcement amounts (to only be activated in case of a collapse). This can be unpractical in many situations, and the combination with anchorage of the flexural reinforcement in the soffit of the slab, bent-up bars, or shear reinforcement is advised (with the last two solutions also contributing to the punching strength).

- According to the test results and theoretical model presented in this paper, the use of high-ductility steel is encouraged for the integrity reinforcement to improve its efficiency.

\section{CONCLUSIONS}

This paper investigates post-punching shear strength of slab-column joints through an experimental and theoretical research. Its main conclusions are:

1. After punching, the residual shear strength can be increased due to the activation of the flexural or integrity reinforcement.

2. Flexural reinforcement provides a limited postpunching capacity when it is not suitably anchored on the soffit of the slab.

3. Straight bars placed in the soffit of the slab over the supported areas (integrity reinforcement) can increase the residual strength of flat slabs. Its activation, however, requires significant column penetration. In addition, to ensure sufficient post-punching strength, fairly large amounts of integrity reinforcement over the columns are usually required.

4. Bent-up bars generally perform better than straight bars. This is justified because they contribute to the punching strength of the slab and have a more favorable angle for their activation as integrity reinforcement after punching.

5. A mechanical model is presented for design of integrity reinforcement that accounts for the influence of flexural and integrity reinforcement. Such a model is in good agreement with test results.

6. On the basis of the previous considerations, it is advised to:
- Combine the integrity reinforcement with bent-up bars, shear reinforcement, or flexural reinforcement developed in the soffit of the slab; and

- Use high-ductility reinforcement for the integrity bars.

\section{ACKNOWLEDGMENTS}

This research was funded by the Swiss Association of the Cement Industry (CEMSUISSE). The financial support and discussions with the scientific committee are kindly acknowledged.

\section{NOTATION}

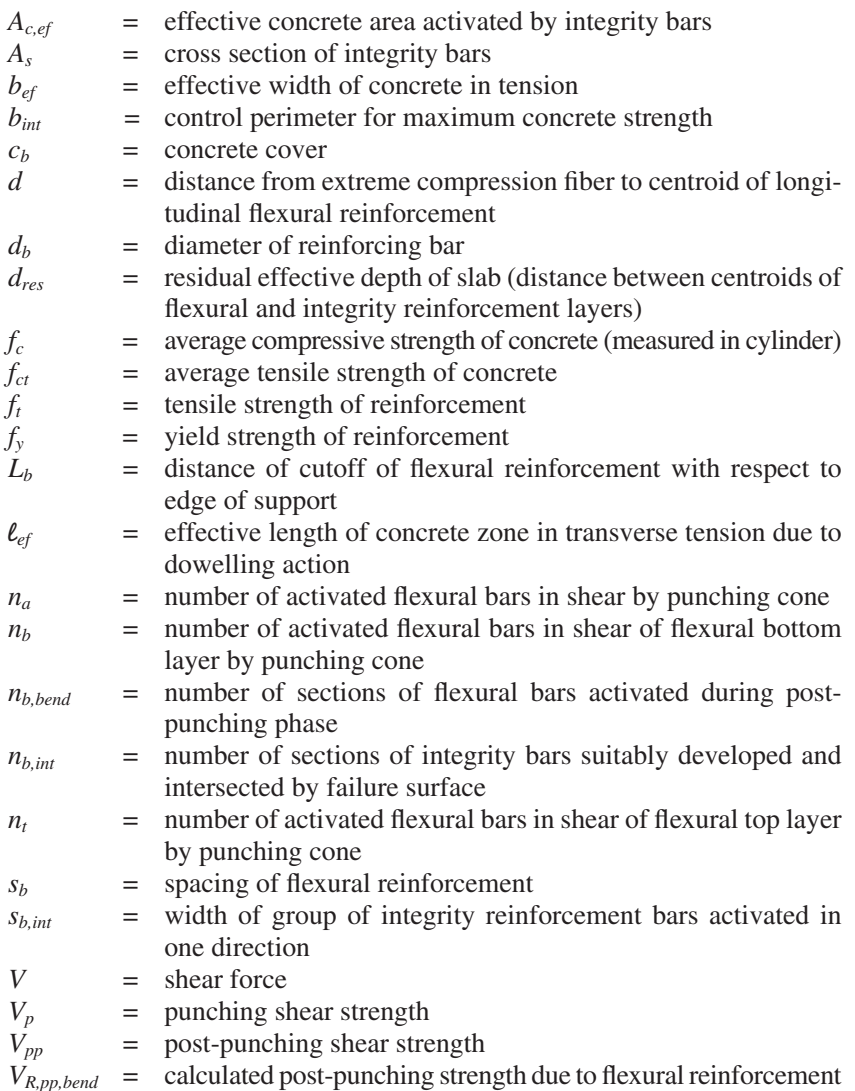


$V_{R, p p, c a l c}=$ calculated post-punching strength

$V_{R, p p, i n t}=$ calculated post-punching strength due to integrity reinforcement

$V_{R, p p, t e s t}=$ maximum recorded load during post-punching reloading

$w_{p} \quad=$ deflection at punching

$w_{p p} \quad=$ deflection at maximum load during post-punching reload

$\beta_{b} \quad=$ angle of bent-up bars

$\varepsilon_{s} \quad=$ steel strain

$\varepsilon_{s u}=$ steel strain at tensile rupture

$\varepsilon_{\text {suk }}=$ characteristic value of steel strain at tensile rupture

$\varepsilon_{t} \quad=$ steel strain at rupture

$\theta \quad=$ angle for calculation of activated flexural bars

$\theta_{\text {bottom }}=$ angle for calculation of activated bars on flexural bottom layer

$\theta_{\text {top }}=$ angle for calculation of activated bars on flexural top layer

$\rho=$ flexural reinforcement ratio

$\sigma_{s} \quad=$ steel stress

$\psi=$ rotation of slab outside column region

$\psi_{t}=$ average angle of integrity bars (deformed shape) with respect to plane of slab

\section{REFERENCES}

1. Muttoni, A.; Fernández Ruiz, M.; Fürst, A.; Guandalini, S.; Hunkeler, F.; Moser, K.; and Seiler, H., Sécurité structurale des parkings couverts (Security of Parking Garages), Documentation D 0226 SIA, A. Muttoni, ed., Société Suisse des ingénieurs et des architectes, Zürich, Switzerland, 2008, 105 pp. (in French)

2. Schousboe, I., "Bailey's Crossroads Collapse Reviewed," Journal of the Engineering Mechanics Division, ASCE, V. 102, June 1976, pp. 365-378.

3. Carino, N. J.; Woodward, K. A.; Leyendecker, E. V.; and Fattal, S. G., "A Review of the Skyline Plaza Collapse," Concrete International, V. 5, No. 7, July 1983, pp. 35-42.

4. Kaminetzky, D., Design and Construction Failures: Lessons from Forensic Investigations, McGraw-Hill, New York, 1991, 600 pp.

5. King S., and Delatte N. J., "Collapse of 2000 Commonwealth Avenue: Punching Shear Case Study," Journal of Performance of Constructed Facilities, ASCE, V. 18, No. 1, Feb. 2004, pp. 54-61.

6. Melo, G. S., "Behaviour of Reinforced Concrete Flat Slabs after Local Failure," PhD thesis, Polytechnic of Central London, London, UK, 1990, 214 pp.

7. Muttoni, A., "Punching Shear Strength of Reinforced Concrete Slabs without Transverse Reinforcement," ACI Structural Journal, V. 105, No. 4, July-Aug. 2008, pp. 440-450.

8. EN 1990:2002, "Eurocode-Basis of Structural Design," Comité Européen de Normalisation, Brussels, Belgium, 2002, 90 pp.

9. Fernández Ruiz, M.; Muttoni, A.; and Kunz, J., "Strengthening of Flat Slabs against Punching Shear Using Post-Installed Shear Reinforcement," ACI Structural Journal, V. 107, No. 4, July-Aug. 2010, pp. 434-442.

10. Fédération Internationale du Béton, "Model Code 2010-First Complete Draft," fédération internationale du béton, Bulletins 55-56, Lausanne, Switzerland, April and May 2010, 318 pp. (Bulletin 55) and 312 pp. (Bulletin 56).

11. Muttoni, A., and Fernández Ruiz, M., "Shear Strength of Members without Transverse Reinforcement as a Function of Critical Shear Crack Width," ACI Structural Journal, V. 106, No. 4, July-Aug. 2009, pp. 485-494.

12. Melo, G. S., and Regan, P. E., "Post-Punching Resistance of Connections between Flat Slabs and Interior Columns," Magazine of Concrete Research, V. 50, No. 4, Dec. 1998, pp. 319-327.
13. Broms, C. E., "Ductility of Flat Plates: Comparison of Shear Reinforcement Systems," ACI Structural Journal, V. 104, No. 6, Nov.-Dec. 2007, pp. 703-711.

14. Tassinari, L., "Poinçonnement non symétrique de dalles en béton armé (Non-Symmetrical Punching of Reinforced Concrete Flat Slabs)," $\mathrm{PhD}$ thesis, École Polytechnique Fédérale de Lausanne, Lausanne, Switzerland, 2011, 156 pp. (in French)

15. Regan, P. E.; Walker, P. R.; and Zakaria, K. A. A., Tests of Reinforced Concrete Flat Slabs, School of the Environment, CIRIA Project RP 220, Polytechnic of Central London, London, UK, 1979, 217 pp.

16. Rasmussen, B. H., "Betonindstobte tvaerbelastede boltes og dornes baereevne (Strength of Transversely Loaded Bolts and Dowels Cast in Concrete," Bygningsstatiske Meddelelser, V. 34, No. 2, 1963, pp. 39-55. (in Danish)

17. McPeake, F. A., "Post-Punching Resistance of Internal Slab-Column Connection," BSc honours project, Department of Civil Engineering, Queen's University of Belfast, Belfast, UK, May 1980, 107 pp.

18. Georgopoulos, T., "Durchstanzlast und Durchstanzwinkel über Innenstützen punktförmig gestützter Stahlbetonplatten und deren Sicherung gegen progressiven Kollaps (Punching of RC Slabs on Inner Columns Subjected to Point Loads and Their Safety against Progressive Collapse)," PhD thesis, Technical University of Munich, Munich, Germany, 1986, 197 pp. (in German)

19. Mitchell, D., and Cook, W. D., "Preventing Progressive Collapse of Slab Structures," Journal of Structural Engineering, ASCE, V. 110, No. 7, July 1984, pp. 1513-1532.

20. Broms, C. E., "Shear Reinforcement for Deflection Ductility of Flat Plates," ACI Structural Journal, V. 87, No. 6, Nov.-Dec. 1990, pp. 696-705.

21. Pralong, J.; Brändli, W.; and Thürlimann, B., "Durchstanzersuche an Stahlbeton und Spannbetonplatten (Punching Tests on Reinforced and Prestressed Concrete Slabs)," Birkhäuser Verlag, Institut für Baustatik und Konstruktion ETH Zürich, Nr. 7305-3, Switzerland, 1979, 89 pp. (in German)

22. Müller, F.-X.; Muttoni, A.; and Thürlimann, B., "Durchstanzversuche an Flachdecken mit Aussparungen (Punching Tests on Flat Slabs with Recesses)," Institut für Baustatik und Konstruktion, ETH Zürich, Report Nr. 7305-5, Birkhäuser Verlag Basel-Boston-Stuttgart, 1984, 118 pp. (in German)

23. Freyermuth, C. L., "Structural Integrity of Buildings Constructed with Unbounded Tendons," Concrete International, V. 11, No. 3, Mar. 1989, pp. 56-63.

24. Ramos, A. P., and Lucio, V. J. G., "Post-Punching Behavior of Prestressed Concrete Flat Slabs," Magazine of Concrete Research, V. 60, No. 4, May 2008, pp. 245-251.

25. Fernández Ruiz, M.; Plumey, S.; and Muttoni, A., "Interaction between Bond and Deviation Forces in Spalling Failures of Arch-Shaped Members without Transverse Reinforcement," ACI Structural Journal, V. 107, No. 3, May-June 2010, pp. 346-354.

26. Dei Poli, S.; di Prisco, M.; and Gambarova, P., "Shear Response, Deformations, and Subgrade Stiffness of a Dowel Bar Embedded in Concrete," ACI Structural Journal, V. 89, No. 6, Nov.-Dec. 1992, pp. 665-675.

27. Mirzaei, Y., "Post-Punching Behavior of Reinforced Concrete Slabs," PhD thesis 4613, École Polytechnique Fédérale de Lausanne, Lausanne, Switzerland, 2010, 203 pp.

28. Broms, C. E., "Elimination of Flat Plate Punching Failure Mode," ACI Structural Journal, V. 97, No. 1, Jan.-Feb. 2000, pp. 94-101. 
